avidly protein bound persists in the tissues. We could not implicate the subcutaneous injection techniques in the patients (Cases 3-9) who developed indurated pruritic transient lesions within hours of injection. Contact sensitization to cresols is recognized, ${ }^{5}$ and we suspect that all local and one of the systemic reactions seen in our patients resulted from hypersensitivity to the chlorocresol preservative. Intradermal skin testing with chlorocresol-preserved heparin gave immediate responses, whereas in only one (Case 1 ) of the tests with preservativefree heparin (Weddel) was there a reaction.

We suggest that in cases of apparent heparin sensitivity treatment may be able to continue without adverse reaction after cautious challenge with chlorocresol-free heparin.

We are grateful to Professor J. Richmond for helpful criticism, and to Mrs. E. C. Baxter (Weddel Pharmaceuticals Ltd.) for useful information.

${ }^{1}$ Moser, R. H., Clinical Pharmacology and Therapeutics, 1968, 9, 255.

2 Richmond, J., personal communication, 1975.

3 O'Toole, R. D., Annals of Internal Medicine, 1973, 79, 759.

${ }^{4}$ Hume, M., Smith-Petersen, M., and Fremont-Smith, P., Lancet, 1974, 1, 261.

5 Fisher, A. A., Contact Dermatitis, 2nd edn., p. 374. Philadelphia, Lea and Febiger, 1972.

Academic Division of Medicine, Royal Hospital, Sheffield S1 3SR B. W. HANCOCK, M.B., M.R.C.P., Lecturer ANNE NAYSMITH, M.B., B.SC., Senior House Officer

\section{Deglutition Syncope}

Syncope provoked by swallowing is rare according to the few cases reported. Probably this condition is not recognized and passes unnoticed. A salient feature of the reported cases is that in most of them disorders of the oesophagus could be shown. These ranged from diverticula ${ }^{1}$ to strictures, ${ }^{2}$ spasm, and carcinoma. ${ }^{3}$ In most cases syncope occurred mainly as a result of atrioventricular heart block, but sinus bradycardia and sinus arrest have also been reported, ${ }^{3}$ and in one case ${ }^{1}$ both sinoatrial and atrioventricular block as well as signs of other disturbances of the sinus node were recorded.

We report a case of what we suggest be termed deglutition syncope characterized by repetitive syncopes during swallowing due to heart block.

\section{Case Report}

A 43-year-old man with a past history of rheumatic fever during childhood had for several years suffered from suddenly occurring retrosternal pain, which occurred mainly during meals but also spontaneously. On many occasions he had fainted, but usually the pain was accompanied only with dizziness. Drinking of carbonated beverages regularly provoked such attacks, but no other food could be pointed out as of particular significance. The general examination, including $x$-ray examination and endoscopy of the oesophagus, was uneventful except for a left anterior hemiblock in the electrocardiogram (E.C.G.). He was monitored in the ward, and on a couple of occasions a marked variation of the heart rate was observed. Over a short period of time the heart rate could vary from 44 to 80 beats/min, showing chaotic atrial activity. A provocation test letting the patient drink carbonated water resulted in a conspicuous sinus arrythmia and bradycardia (see fig.).

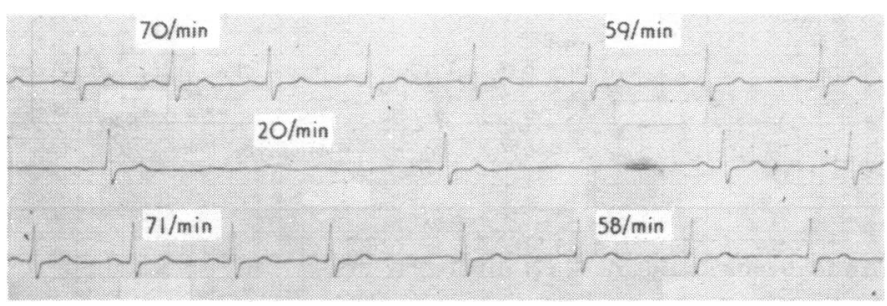

E.C.G. telemetry while swallowing, showing changing P-wave configuration and frequency slowing from 70 to 20 beats/min.
E.C.G. registration with an oesophageal lead produced atrioventricular blockade. Because of these defects of the conduction system of the heart we decided to implant an on-demand pacemaker. A control later on with inhibition of the implanted pacemaker and with the patient simultaneously drinking carbonated water showed the occurrence of an asystole lasting $3 \cdot 7$ seconds.

\section{Comment}

Local changes of the oesophagus have been considered the cause of an enhanced sensitivity of the nervous receptors so that a vagovagal reflex might be put at work with resultant heart block. Such disorders, however, are not always demonstrable, as in this report, and they alone are hardly responsible for deglutition syncope or similar conditions. The prime factor in this condition is probably a disease of the conduction system of the heart. This is supposed to exist at a subclinical level, but can be triggered by nervous reflexes originating in the oesophagus. This also applied to our patient, who according to current views suffered from the sick-sinus syndrome but who in addition displayed an atrioventricular blockade during stimulation of the nervous receptors of the oesophagus.

Deglutition can also provoke tachyarrhythmias, ${ }^{2}{ }^{4}$ and in one reported case $^{2}$ swallowing initially produced a tachycardia of 140 beats $/ \mathrm{min}$. This suddenly changed into a sinus bradycardia of 45 beats $/ \mathrm{min}$ and syncope, but asystole did not ensue. By definition a sick sinus produces both tachyarrhythmias and bradyarrhythmias.

It is important to recognize deglutition syncope since such syncopes may be life-threatening and easily can be prevented by insertion of a pacemaker.

:James, A. H., Lancet, 1958, 1, 771 .

2 Tolman, K. G., and Ashworth, W. D., Digestive Diseases, 1971, 16, 1026. 3 Tomlinson, I. W., and Fox, K. M., British Medical fournal, 1975, 2, 315.

'Bajaj, S. C., et al., Gastroenterology, 1972, 62, 632.

Medical Department, St. Josephs Hospital, 3900 Porsgrunn, Norway B. WIK, M.D., Physician

L. HILLESTAD, M.D., Physician

\section{Septic Abortion Associated with a Lippes Loop}

Septic abortion associated with an intrauterine contraceptive device (I.U.D.) has been well documented in the United States. ${ }^{1}$ The Dalkon Shield has been mainly concerned with this complication ${ }^{23}$ and the Food and Drug Administration suspended sales of it in the U.S.A. in June 1974. Subsequently the F.D.A. has reported 219 septic abortions and 13 deaths in association with this device. These serious complications have not been confined exclusively to the Dalkon Shield, however, and this paper reports a case of septic abortion with a Lippes Loop.

\section{Case Report}

A 26-year-old woman at 21 weeks gestation in her third pregnancy was admitted with a history of pyrexia and rigors for 24 hours and abdominal pain and vaginal bleeding of increasing severity for eight hours. She had had a Lippes Loop I.U.D. inserted two years earlier, six months after a normal pregnancy. Her first pregnancy had been terminated at 10 weeks. The current pregnancy had been uneventful up to the time of admission and she denied interference.

On admission she was severely distressed and pale. Her temperature was $38.5^{\circ} \mathrm{C}$; the blood pressure was $110 / 70 \mathrm{~mm} \mathrm{Hg}$ and the pulse rate 130 beats/ min. There was moderate lower abdominal tenderness and the uterus, the size of which was compatible with the stated period of gestation, was contracting strongly every five minutes. Vaginal bleeding was moderate; membranes bulged through the cervix, which was $2-\mathrm{cm}$ dilated. The haemoglobin was $9.6 \mathrm{~g} / \mathrm{dl}$ and the total leucocyte count $12.3 \times 10^{9} / 1$. Blood cultures subsequently grew Proteus spp. She was transfused two pints $(1 \cdot 1 \mathrm{l})$ of blood. Ampicillin treatment, started before admission, was continued by intramuscular injection. She spontaneously aborted two hours after admission. 